\title{
Structural Modeling of A Five-Meter Thin Film Inflatable Antenna/Concentrator With Rigidized Support Struts
}

\author{
Kurt B. Smalley $\dagger$ \\ Department of Mechanical Engineering \\ Clarkson University \\ Potsdam, NY
}

\author{
Michael L. Tinker $\ddagger$ \\ Structural Dynamics and Loads Group/ED21 \\ Structures, Mechanics, and Thermal Department \\ NASAMarshall Space Flight Center \\ Huntsville, AL 35812
}

\begin{abstract}
Dynamic characterization of a non-rigidized thin film inflatable antenna/solar concentrator structure with rigidized composite support struts is described in detail. A two-step finite element modeling approach in MSC/NASTRAN is utilized, consisting of (1) a nonlinear static pressurization procedure used to obtain the updated stiffness matrix, and (2) a modal "restart" eigen solution that uses the modified stiffness matrix.

Unique problems encountered in modeling of this large 5-m lightweight inflatable are identified, including considerable difficulty in obtaining convergence in the nonlinear pressurization solution. It was found that the extremely thin polyimide film material $(.001$ in or $1 \mathrm{mil})$ presents tremendous problems in obtaining a converged solution when internal pressure loading is applied. It was concluded that the ratios of film thickness to other geometric dimensions such as torus cross-sectional and ring diameter and lenticular diameter are the critical parameters for convergence of the pressurization procedure.

Comparison of finite element predictions for frequency and mode shapes with experimental results indicated reasonable agreement considering the complexity of the structure, the film-to-air interaction, and the nonlinear material properties of the film. It was also concluded that analysis should be done using different finite element to codes to determine if a more robust and stable solution can be obtained.
\end{abstract}

\section{Introduction and Background}

Inflatable structures have been the subject of renewed interest in recent years for space applications such as communications antennas, solar thermal propulsion, and

†Student of Mechanical Engineering

$\ddagger$ Aerospace Technologist, Structural Dynamics; Associate Fellow AIAA

Copyright $\Theta 2001$ by the American Institute of Aeronautics and Astronautics, Inc. No copyright is asserted in the United States under Title 17, U.S. Code. The U.S. government has a royalty-free license to exercise all rights under the copyright claimed herein for Governmental purposes. All other rights are reserved by the copyright owner. space solar power (Figs. 1-2). A major advantage of using inflatable structures in space is their extremely light weight. An obvious second advantage is on-orbit deployability and subsequent space savings in the launch configuration. A recent technology demonstrator flight for inflatable structures was the Inflatable Antenna Experiment (IAE) that was deployed on orbit from the Shuttle Orbiter. Although difficulty was encountered in the inflation/deployment phase, the flight was successful overall and provided valuable experience in the use of such structures (Ref. 1).

The Solar Orbital Transfer Vehicle (SOTV), discussed in Ref. 2, and Solar Thermal Upper Stage (STUS), described in Refs. 3-5, are possible technology demonstrator flights for solar thermal propulsion. The basic concept behind solar thermal propulsion is to utilize sunlight or solar energy as a means of heating a working fluid (propellant) to provide thrust at increased specific impulse. As described in Ref. 6, thrust is produced by expanding the heated propellant through a nozzle. No combustion occurs, and the thrust level is low. For this reason, solar thermal propulsive systems are mainly applicable for orbital transfer vehicles. The engine system envisioned for the STUS is designed to utilize hydrogen propellant to produce a thrust level of about $2 \mathrm{lbf}$. Two inflatable parabolic collectors could be used that would be rotated and gymballed for focusing sunlight into an absorber cavity (Fig. 1, from Ref. 5). The collectors would be inflated after separation of the upper stage from the launch vehicle.

Many investigators have considered the use of inflatable structures for space applications. Perhaps the earliest was Frei Otto (Ref. 7), who in 1962 published ideas for inflated tubular frames for use in structures such as orbiting platforms. A more recent proposed application involves the use of inflatable beam segments to replace solid segments of the Space Shuttle remote manipulator system and thus reduce storage space and inertia of the arm (Ref. 8).

Several papers on static structural analysis of inflated cylinders have been written, describing different techniques such as linear shell theory, and nonlinear and variational methods (Refs. 9-17), but very little work had been done in dynamics of inflatable structures until recent years. In 1988 Leonard (Ref. 18) indicated that elastic beam bending modes could be utilized in approximating lower-order frequencies of inflatable beams. Main, et al. wrote a very significant 1995 paper describing results of modal tests of 
inflated cantilever beams and the determination of effective material properties (Ref. 19). Changes in material properties for different pressures were also discussed, and the beam model was used in a more complex structure. The paper demonstrated that conventional finite element analysis packages could be very useful in the analysis of complex inflatable structures. Reference 20 describes an investigation of the dynamics of polyimide thin-film inflated cylinders, and Refs. 21-29 discuss recent dynamic tests/analyses and potential applications of inflatable solar concentrators.

\section{Description of Inflatable Collector Investigated in the Current Study}

In Figs. 3 and 4, a prototype circular 5-m inflatable collector manufactured by SRS Technologies, Inc. is shown that consists of a pressurized lenticular/torus assembly supported by three solid composite struts. The lenticular has 190-in. diameter, and the torus has 252-in. outside diameter and 24 -in. cross-sectional diameter. This collector can function as a space-based antenna for communications, surveillance, and radiometry, or as a solar concentrator assembly for solar thermal propulsion systems. The inflatable lenticular and torus elements are constructed of NASA Langley Research Center's CP-1 and DuPont's Kapton polyimide films, respectively, each of which is .001 in (1 mil) thick. Silicon-backed Kapton is the adhesive used for joints in the inflatable structures. A reflective coating on the inner lenticular CP-I film provides the means of collecting radio waves or solar energy. It is noted that the particular application for the antenna/concentrator depends on the surface accuracy of the reflective lenticular surface. Use as an optical system would require greater surface accuracy than a solar concentrator for propulsion systems, for example.

The tapered composite struts for the prototype structure were formed by layering of an impregnated fabric, and have solid cross-sections varying from 8 in. diameter at the fixed ends to $4 \mathrm{in}$. diameter at the torus attach points. All three struts extend from the torus at 45 degrees and toward a point 101 in. from the torus/lenticular midplane. It is noted that for spaceflight configurations, the struts would likely be inflatable/rigidizable with hollow cross-sections. Following inflation and deployment in space, the struts would harden upon exposure to sunlight or another rigidizing agent. In the configuration of Fig. 4, the support struts are attached to a composite circular base plate.

In the case of solar thermal propulsion applications (Fig. 1), the collector assembly would focus sunlight into an absorber or secondary concentrator near the fixed ends of the struts. Solar energy stored in the absorber could be utilized to heat a propellant and generate thrust as described previously.

Inflatable structures in general are extremely lightweight and the collector described in this paper is no exception. The thin-film inflatable part of the concentrator weighs approximately $7.5 \mathrm{lb}$, and the total weight including the struts is on the order of $20 \mathrm{lb}$.

\section{Test Configuration and Results}

For modal testing, the inflatable structure with supporting struts was mounted on a stand (Fig. 4) by means of the circular base plate described in a previous section. The stand itself is a truss structure of composite beams anchored with three large metal plates resting on a concrete floor. The heavy metal plates were required due to the impossibility of bolting the stand directly to the floor.

Due to high flexibility of the polyimide film at any location on the inflated part of the collector, and based on previous experience, it was decided to utilize shaker excitation at a location on one of the struts (Fig. 4). It has been found that excitation applied directly on the inflatable surface typically is not successful for modal measurements.

Accelerometers were used on the composite struts and support stand for measuring frequency response. However, in order to avoid mass-loading of the inflatable lenticular and torus elements, a non-contact scanning laser vibrometer was employed. Figure 5 shows the approximate location of the laser vibrometer relative to the test article for one series of measurements.

Response measurements on the surface of the inflatable torus were complicated by the fact that the polyimide material is optically transparent, allowing much of the laser light to pass through the test article. In addition, the laser beam must be as close to perpendicular as possible with respect to the test article surface in order to minimize any degradation in vibrometer measurements. This is true because the vibrometer is designed to measure the test article motion along the direction of the laser beam, and if the laser is not truly perpendicular to the surface, only a component of the real motion is measured.

To solve the first problem described in the previous paragraph, surface treatments were used to facilitate testing. Reflective aluminum tape was mounted at all measurement points on the torus and lenticular elements. On the inflatable torus the reflective tape was formed in the shape of "corner cubes" whose perpendicular sides allowed measurements in the plane of the torus and perpendicular to it. The second difficulty discussed in the previous paragraph, misalignment of the laser beam relative to the direction normal to surfaces of the inflatable, was mitigated by placing the vibrometer large distances from the structure. This distance varied from about $40 \mathrm{ft}$ to $100 \mathrm{ft}$ depending on the direction of measurements.

Modal data was obtained for the test configuration as described in this section at room temperature for inflation pressures of 0.061 and .00065 psig. in the torus and lenticular, respectively. As a note of interest, the extremely low pressure in the inflated lenticular element leads some researchers to believe that optical structures of this type can compensate for meteroid/debris damage by carrying on-board makeup gas. However, the higher torus 
pressure likely means that inflatable support structures such as struts and torus elements will have to be rigidized for practical long-term use in space.

Modal parameters were successfully identified for the first seven natural frequencies of the integrated structure. The resulting modal properties are given in Table 1 , and show characteristics seen in previous inflatable concentrator modal tests done at MSFC, primarily the heavy $(\gg 1 \%)$ damping of lower order modes. Representative test mode shapes will be shown in the final paper.

\section{Modeling Approach and Results}

The finite element modeling technique involved two main steps: 1. Nonlinear static analysis, in which the internal pressure loading was applied to the lenticular and torus elements, and 2. Modal analysis utilizing the results of step 1. Such a procedure is needed due to the impossibility of active forces in an eigensolution. In step 1 , the stiffness matrix of the model is updated to capture the tensioning of the thin film material caused by internal pressure. This two-step modeling and analysis methodology is described in detail in Ref. 29, where results are given for inflatable cylindrical beams.

The lenticular and torus films were modeled using NASTRAN quadrilateral plate elements, each of which were .001 in. (1-mil) thick. Modulus, density, and Poisson's ratio as used were provided by the film manufacturers. The CP-1 film has $E=315 \mathrm{ksi}, v=0.34$, and $\rho=0.0517 \mathrm{lbm} / \mathrm{in}^{3}$, while for Kapton Type $H$ film $E=430 \mathrm{ksi}, v=0.34$, and $\rho=0.0512 \mathrm{lbm} / \mathrm{in}^{3}$. Internal pressure of 0.018 in. $\mathrm{H}_{2} \mathrm{O}(.00065 \mathrm{psig})$ and $1.7 \mathrm{in.} \mathrm{H}_{2} \mathrm{O}$ (.061 psig) was applied to lenticular and torus elements, respectively.

Modeling of the solid-section composite struts was done using beam elements, for which the mass and stiffness properties were estimated and maintained as parameters to be updated during model verification. Preliminary assessment of test data showed the inflatable structure modes being largely controlled by the composite struts. Overall model verification and refinement may well focus on improving the accuracy of the strut models.

The composite support stand shown in Fig. 4 was modeled rather crudely using beam elements. However, preliminary examination of test modes for the inflatable assembly showed that the first several modes were relatively insensitive to stand dynamics. It was expected that relatively little modification or refinement of the stand model would be needed during overall model verification and updating.

The mass properties of the model are interesting, particularly the inflatable components. In the case of the lenticular, the total weight was $19.8 \mathrm{lb}$, of which $16.2 \mathrm{lb}$ was the weight of air contained inside the structure. For the torus, the total weight was $21.6 \mathrm{lb}$, and the weight of air was $14.2 \mathrm{lb}$. Thus of a total combined weight of 41.4 $\mathrm{lb}$ for the inflatable components, $30.4 \mathrm{lb}$, or 73 percent, was attributed to the internal air. The test stand and composite struts weighed a combined $1185 \mathrm{lb}$, such that the integrated model had a total weight of $1228 \mathrm{lb}$. Figure 6 shows the integrated finite element model.

The greatest difficulty encountered in modeling and analysis was obtaining convergence of the nonlinear static pressurization solution in MSC/NASTRAN. This difficulty is due to the the extremely thin polyimide material of which the inflatable components are constructed ( 1 mil or $1 / 1000$ of one inch). The ratios of film thickness to overall geometric dimensions such as torus cross-sectional and major diameter and lenticular diameter appear to be the critical parameters in the nonlinear pressurization analysis. For example, it was found that increasing the film thickness to $10 \mathrm{mils}$ or $1 / 100$ in. resulted in solutions that converged easily. The reason for this phenomenon appears to be that extremely thin films tend to have large displacements and large stiffness changes when pressure loading is applied. Obviously, increased thickness reduces the magnitude of these changes.

It was discovered that the model had to be constrained at a large number of points strategically located on the film surface to obtain convergence of the pressurization solutions. Figure 7 shows the constraint points used for the lenticular structure. These points were then released in the modal "restart" of NASTRAN, the second step in the analysis procedure.

Interestingly, the analysis for inflatable cylindrical struts described in Ref. 29 revealed fewer problems with the convergence issue. The film thickness was 2 mils (.002 in), comparable to that for the 5-meter structure described in this paper, but the struts were much smaller in overall size, having 6-in. cross-sectional diameter, and 8-ft. length. Reference 29 provides an extensive discussion of the convergence issue encountered in these modeling efforts.

After all the difficulties encountered in this modeling and analysis effort, it was satisfying to obtain results that agreed reasonably well with test data in initial comparisons. The first natural frequency of the integrated model was $1.45 \mathrm{~Hz}$, and the mode shape was characterized by side-to-side flexing of the composite struts with the inflatable components moving rigidly with the struts. The first few modes were similar in that the torus and lenticular moved rigidly while the struts were bending. Coupled support structure and inflatable structure modes were seen in the $8 \mathrm{~Hz}$ range, and torus ring modes appeared in the $12 \mathrm{~Hz}$ range. Figures 8 and 9 show a lower-order global mode of the structure, and a higherorder mode in which localized lenticular motion dominates. In modal testing, the first several modes were obtained as described previously. The analytical mode shown in Fig. 8 compares fairly well with the fundamental test mode. Further comparisons will be made in the future and model updating and correlation with the test data will be accomplished. 


\section{Summary}

Modeling of a large 5-m thin-film inflatable collector structure has been accomplished, and initial comparisons made with test data. This work is significant because of (1) general difficulty in accurately representing the nonlinear material and geometric characteristics of these structures, (2) the large size of this thin-film structure, and most importantly, (3) the accomplishment of a modeling methodology that realistically represents the internal pressure loading and the stiffness properties of the thin films in a modal solution.

It was shown that many workarounds were required to obtain convergence of the nonlinear static pressurization procedure in NASTRAN. In this regard, NASTRAN was found to have limitations in its nonlinear analysis capability, particularly for large thin-film structures of the type investigated in this paper. It is recommended that other finite element codes be investigated for modeling of inflatable structures that may be more suitable for such nonlinear analysis.

\section{Acknowledgments}

SRS Technologies is acknowledged for design and construction of the $5-\mathrm{m}$ structure which was the object of investigation in this paper. Jennie McGee provided useful information needed for modeling of the structure, and Jim Moore provided information related to its potential applications.

John Lassiter and Robert Engberg of Marshall Space Flight Center's Structures, Mechanics, and Thermal Department conducted the dynamic testing and provided the modal test data cited in this paper.

\section{References}

1. Freeland, Robert E., "Inflatable Antenna Flight Experiment Experiences", NASA Solar Thermal Propulsion Workshop Proceedings, NASA Marshall Space Flight Center, Huntsville, AL, March 19-20, 1997.

2. Partch, Russell, "Solar Thermal Propulsion Program at Phillips Lab", NASA Solar Thermal Propulsion Workshop Proceedings, NASA Marshall Space Flight Center, Huntsville, AL March 19-20, 1997.

3. Stewart, Jesse F., and Martin, James A.,"Dual Fuel Solar Thermal Stage: Ideal Analysis", Journal of Spacecraft and Rockets, Vol. 33, No. 5, 1996, pp. 752754.

4. Patel, S., and Emrich, W. J., Jr., "Solar Thermal Upper Stage (STUS) Feasibility Study", Proceedings of ASME/JSME/JSES International Solar Energy Conference, Maui, HI, March 1995.

5. Hawk, C.W., Adams, Alan M., et al., "Conceptual Design of a Solar Thermal Upper Stage (STUS) Flight Experiment", AIAA Paper 95-2842.

6. Curtis, Leslie, "NASA Solar Thermal Propulsion Project", NASA Solar Thermal Propulsion Workshop
Proceedings, NASA Marshall Space Flight Center, Huntsville, AL, March 19-20, 1997.

7. Otto, Frei, Tensile Structures, Massachusetts Institute of Technology, Cambridge, MA, 1962.

8. McCarty, L.H., "Inflatable Arm Segments May Lighten Shuttle's Manipulator System", Design News 46(4), pp. 150-151, 1990.

9. Leonard, R.W., Brooks, G.W., and McComb, H.G., Jr., "Structural Considerations of Inflatable Reentry Vehicles", NASA Technical Note D-457, 1960.

10. Topping, A.D., "Shear Deflections and Buckling Characteristics of Inflated Members", Journal of Aircraft, 1(5), pp. 289-293, 1964.

11. Bulson, P.S., "Design Principles of Pneumatic Structures", Structural Engineering, 51(6) pp. 209-215. 1973.

12. Douglas, W.J., "Bending Stiffness of an Inflated Cylindrical Cantilever Beam", AIAA Journal, 7(7), pp. 1248-1253, 1969.

13. Steeves, E.C., "A Linear Analysis of the Deformation of Pressure Stabilized Tubes", U.S. Army Natick Laboratories Report, AD/A-006 493, NTIS, N75-32513.

14. Fichter, W.B., "A Theory for Inflated Thin-Wall Cylindrical Beams", NASA Technical Note D-3466, June 1966.

15. Comer, R.L., and Levy, S., "Deflections of an Inflated Circular-Cylinder Cantilever Beam", AlAA Journal, 1(7), pp. 1652-1655, 1963.

16. Webber, J.P.H., "Deflections of Inflated Cylindrical Cantilever Beams Subjected to Bending and Torsion", Aeronautical Journal 86(858), pp. 306-312. 1982.

17. Main, J.A., Peterson, S.W., and Strauss, A.M., "Load-Deflection Behavior of Space-Based Inflatable Fabric Beams", Journal of Aerospace Engineering, 7(4). 1994.

18. Leonard, J.W., Tension Structures, McGrawHill, New York, 1988.

19. Main, J.A., Carlin, R.A., Garcia, E., Peterson, S.W., and Strauss, A.M., "Dynamic Analysis of SpaceBased Inflated Beam Structures", Joumal of the Acoustical Society of America, 97(2), pp. 1035-1045. Feb. 1995.

20. Slade, Kara N., and Tinker, Michael L., "Analytical and Experimental Investigation of the Dynamics of Polyimide Inflatable Cylinders", AIAA99-1518, Proceedings of the 40th Structures, Structural Dynamics, and Materials Conference, April 12-15, 1999, St. Louis, MO.

21. Tinker, Michael L., "Passively Adaptive Inflatable Structure for the Shooting Star Experiment", AIAA-98-1986, Proceedings of the 39th Structures, Structural Dynamics, and Materials Conference, April 20-23, 1998, Long Beach, CA.

22. Lassiter, John, "Shooting Star Experiment Prototype Inflatable StruU/Torus Assembly Modal Survey", ED73(97-69), NASA Marshall Space Flight Center, Huntsville, AL, June 1997. 
23. Engberg, Robert, and Lassiter, John, "Shooting Star Experiment, Pathfinder 2, Inflatable Concentrator Modal Survey in Vacuum Conditions", Dynamics Test Branch, Marshall Space Flight Center Test Report SSE-DEV-ED97-120, March, 1998.

24. Engberg, Robert, and Lassiter, John, "Shooting Star Experiment, Pathfinder 3, Inflatable Concentrator Modal Survey in Thermal-Vacuum Conditions", Dynamics Test Branch, Marshall Space Flight Center Test Report SSE-DEV-ED97-115, February, 1998.

25. Engberg, Robert, and Lassiter, John, "Shooting Star Experiment, Pathfinder 3, Inflatable Concentrator Terminator Test, Dynamics Test Branch, Marshall Space Flight Center Test Report SSE-DEV-ED98-046, July, 1998.

26. Lassiter, John O., and Engberg, Robert, "Dynamic Testing of an Inflatable Structure Under Thermal-Vacuum Conditions", AIAA-99-1519, Proceedings of the 40th Structures, Structural Dynamics, and Materials Conference, April 12-15, 1999, St. Louis, MO.

27. Slade, Kara N., Tinker, Michael L., Lassiter, John O., and Engberg, Robert, "Comparison of Dynamic Characteristics for an Inflatable Solar Concentrator in Atmospheric and Thermal Vacuum Conditions", AIAA-2000-1641, Proceedings of the 41st Structures, Structural Dynamics, and Materials Conference, April 3-7, 2000, Atlanta, GA.

28. Slade, Kara N., "Dynamic Characterization of Thin Film Inflatable Structures", Ph.D. Dissertation, Duke University, Dept. of Mechanical Engineering and Materials Science, Durham, NC, 2000.

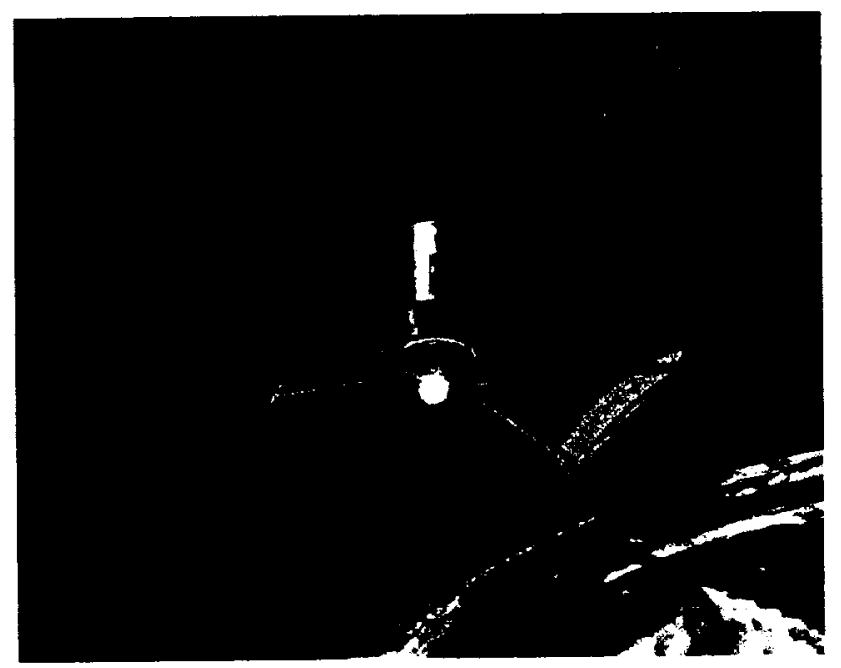

Figure 1. Concept for Solar Thermal Upper Stage Utilizing Inflatable Solar Concentrators

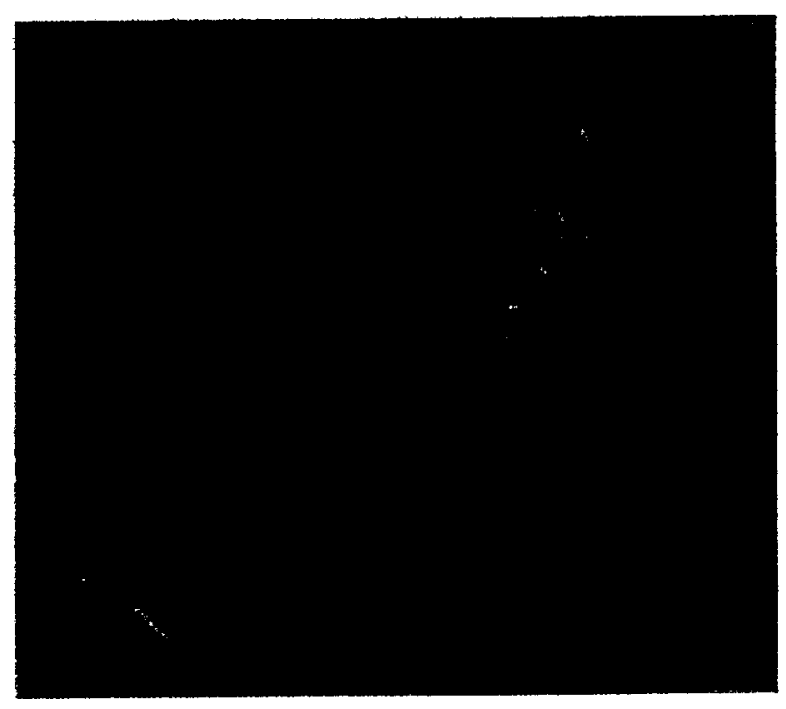

Figure 2. Space Solar Power Concept Based on Inflatable Structures

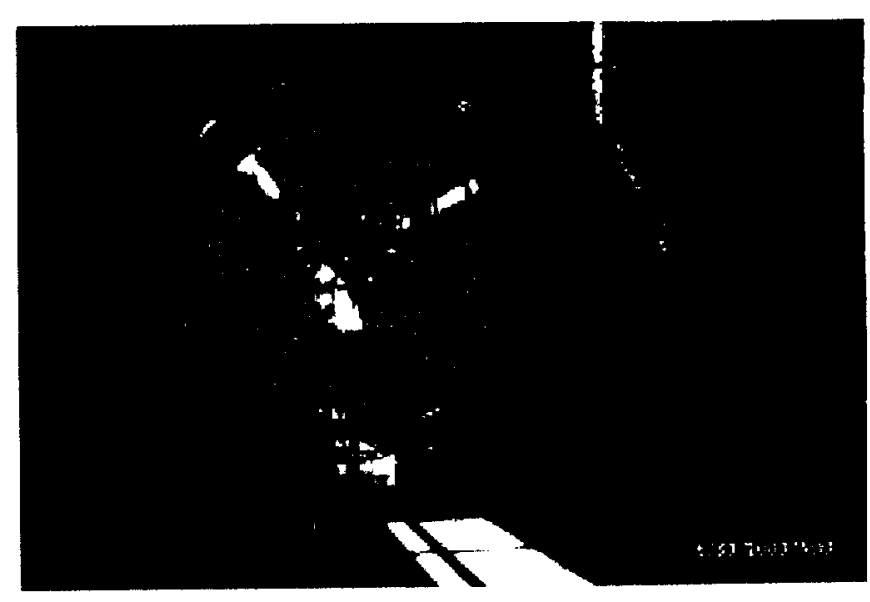

Figure 3. Front View of 5-Meter Thin-Film Inflatable Collector 


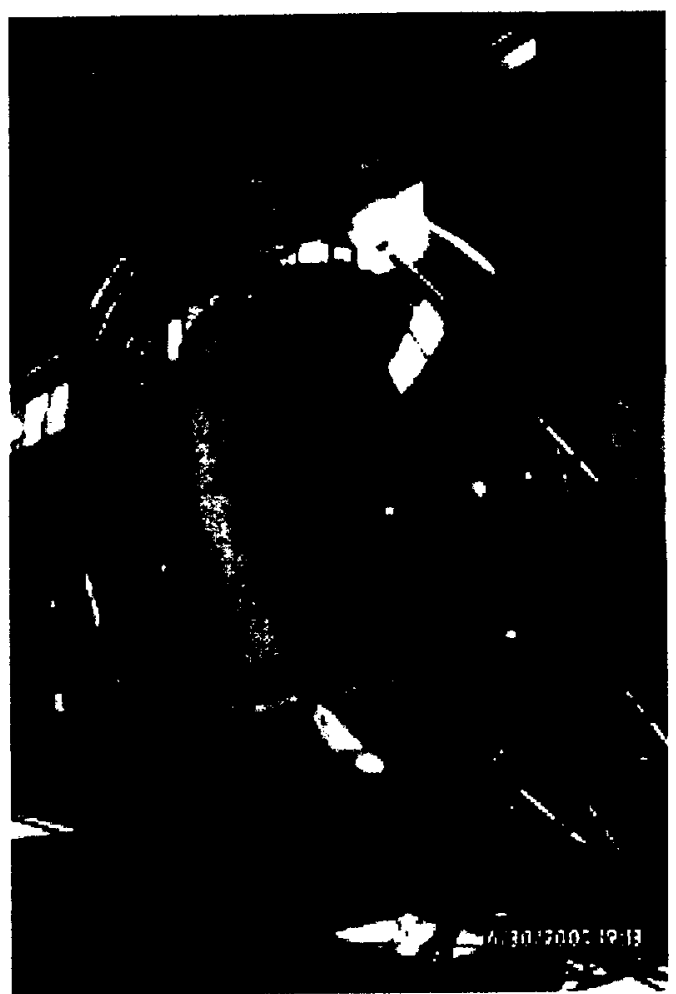

Figure 4. Rear View of 5-Meter Inflatable Collector with Tapered Composite Struts and Support Stand

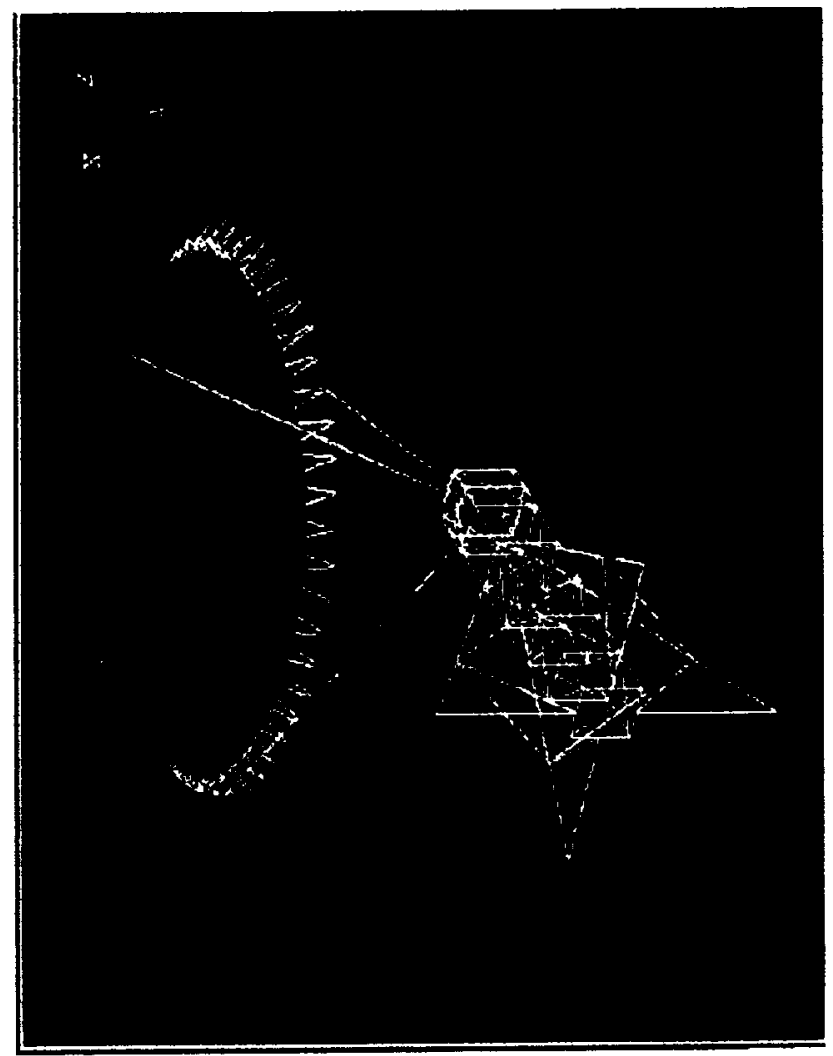

Figure 6. Finite Element Model Representation of Inflatable Collector Shown in Figure 4

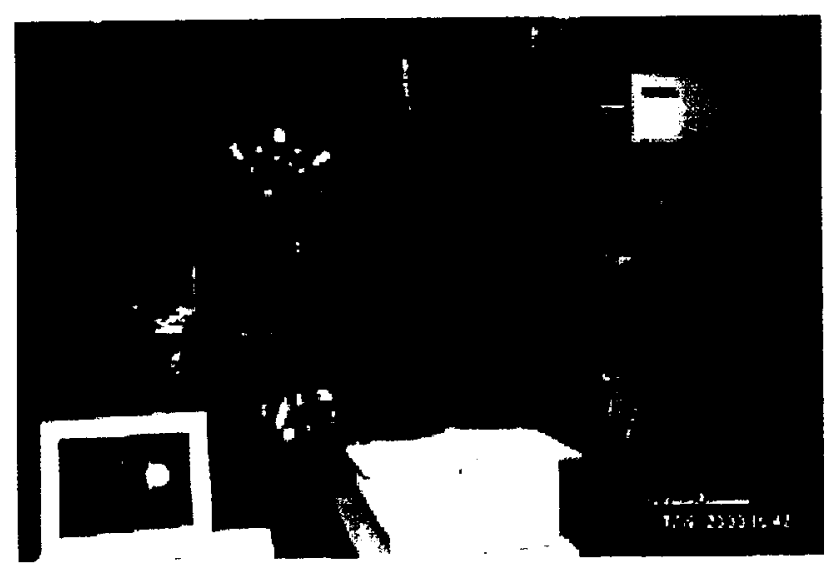

Figure 5. Laser Vibrometer Configuration for Dynamic Measurements on Inflatable Components

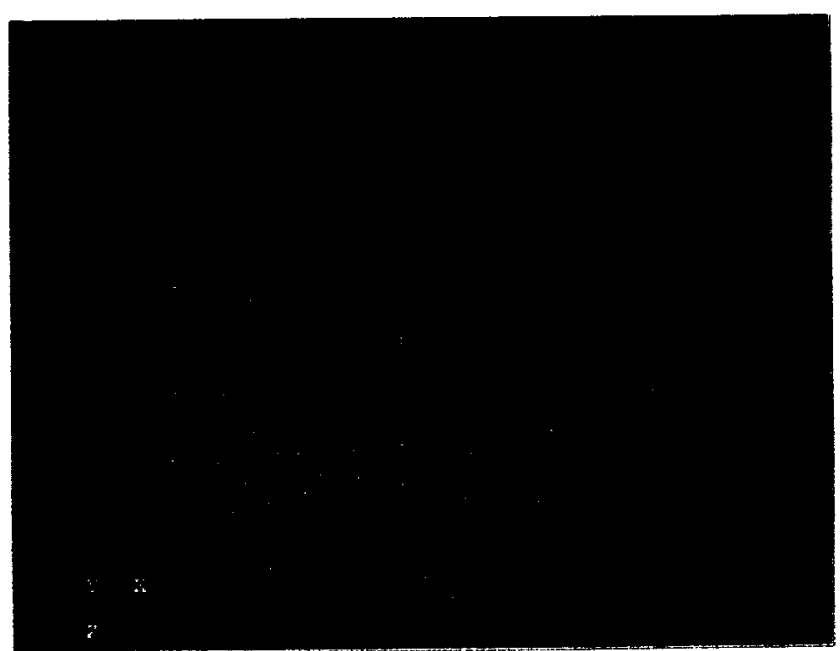

Figure 7. Constraint Points on the Lenticular Structure for Obtaining Convergence of Nonlinear Static Pressurization Solution 


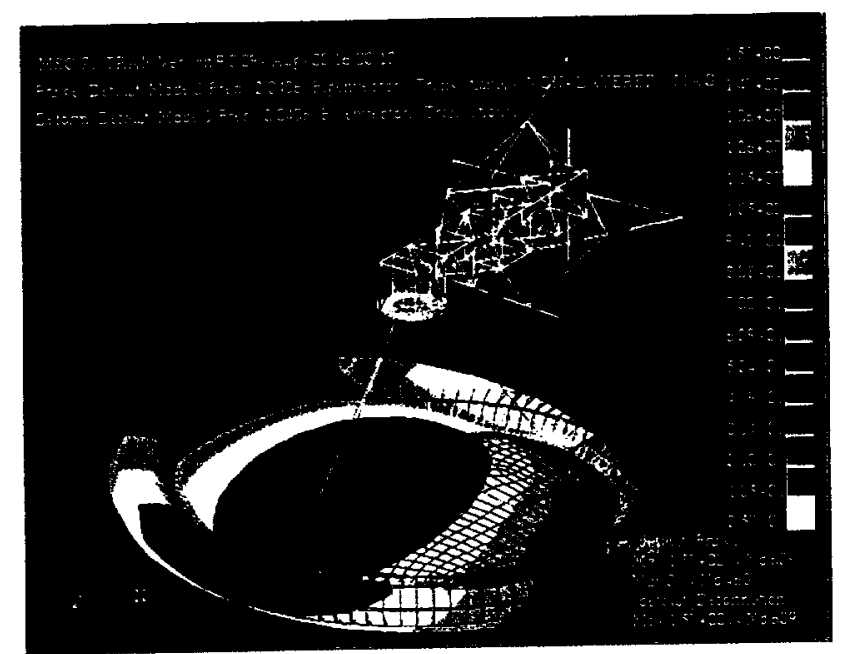

Figure 8. Model Mode Shape with Best Comparison to Fundamental Test Mode

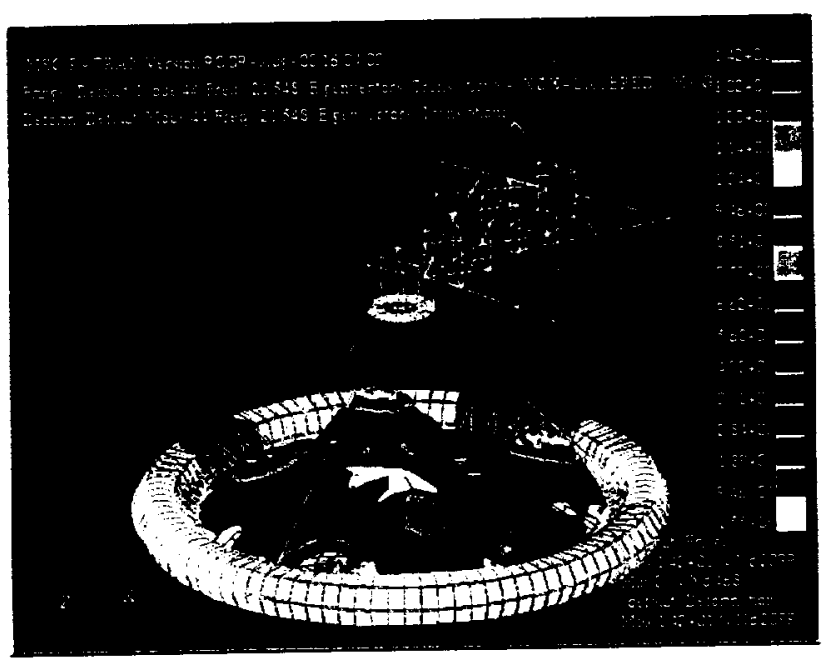

Figure 9. Higher-Order Mode Shape of Model with Localized Lenticular Motion 